\title{
CONSTRUCTION OF A CAUSEWAY BRIDGE ACROSS THE LAKE URMIA AND ITS INFLUENCE ON DRYING TREND OF THE LAKE
}

\author{
M.Ghadimi ${ }^{\mathrm{a}}$, M. A. Nezammahalleh ${ }^{\mathrm{b} *}$ \\ ${ }^{a}$ Assistant professor of geomorphology, Faculty of Geography, University of Tehran, Tehran, Iran.ghadimi@ut.ac.ir \\ bPhD candidate in geomorphology, Faculty of Geography, University of Tehran, Tehran, Iran. mnezammahalleh@ut.ac.ir
}

KEY WORDS: Causeway Bridge, Lake Urmia, T-Test, Precipitation, Playa

\begin{abstract}
:
Construction of a causeway bridge on the Lake Urmia accelerated the drying trend of the largest hyper-saline lake of the world. The objective of the research is to investigate the differences of precipitation and river discharge before and after initiation of the construction of the bridge in 2000. The study area was the watershed of the lake. The averages of the precipitation data in the two periods before and after the project have been interpolated by IDW based on GIS Geostatistical Analyst. The two interpolated precipitation layers were used to be plugged into Student T-test equation in GIS in a spatial basis. To do this, the study area was divided to 25 regions based on drainage sub-basins. Less than 30 sample areas were randomly selected as cases from each of the regions to put into the equation. The discharge data were also compared for the two periods. The results indicated that except in some limited areas, the precipitation differences in the two periods are significant. This means that there were little changes in precipitation and river discharge in the area and consequently the drying may be caused mainly by hydrodynamic changes in the lake due to construction of the causeway. However, it can be argued that the changes in the lake's surface area are accompanied by changes in precipitation and river discharge. The t test statistic can be applied samples based on spatial analysis.
\end{abstract}

\section{INTRODUCTION}

The Lake Urmia is considered as the largest hypersaline lake in the world and the largest lake in the Middle East (UN Environment Programme, 2012;). It (Lake Orumieh) was formed in the last glacial period and has water level fluctuations about 1 meter and diurnal fluctuations about 4 meters (Alavipanah and Nezammahalleh, 2013; Sima and Tajrishy, 2013).

The construction of a causeway bridge across the Lake Urmia affects the drying trend of the Lake and converts it to a playa. The drying trend of the lake as the largest hyper saline lake of the world has been intensified in the recent years. This drying trend can cause many harmful consequences on the environment and human health. After construction of the causeway road dividing the lake into two northern and southern parts in the early 2000, the decreasing trend in the surface area of the lake has accelerated. This acceleration might be due to either a decline in precipitation and discharge or hydrodynamic changes (Ghahroudi and Nezammahalleh, 2013) influenced by construction of the causeway. Some of the changes may be resulted also from climatic and atmospheric factors (Jalili et al., 2011). Therefore, the purpose of this study is to investigate the differences of precipitation and river discharge before and after initiation of the construction of the bridge in 2000 in the drainage basin of the lake i.e. the study area.

\section{MATERIALS AND METHODS}

The Lake Urmia is located in the northwestern area of Iran mainly between two provinces of West Azerbaijan and East Azerbaijan. The lake has been being recently dried and in the near future only a playa surface will remain, that can be called as the Urmia Playa.

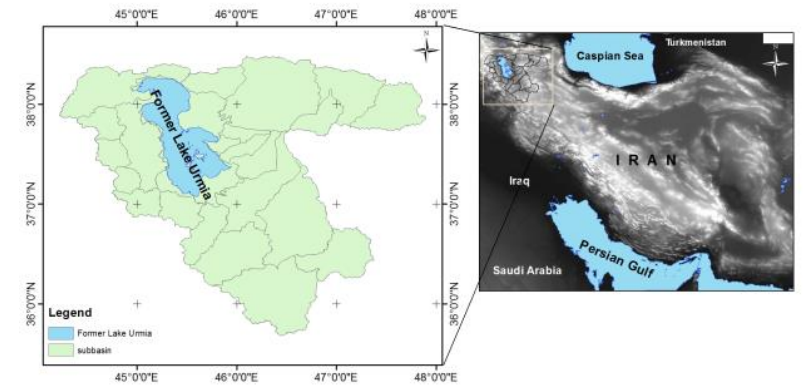

Figure 1: position of the former Lake Urmia

In this research, we have used precipitation data of 16 climatic stations, discharge data of hydrometric stations and Landsat satellite images. The averages of the precipitation data in the two periods before and after initiation of the causeway project (Zeinoddini et al., 2009) have been interpolated by IDW based on GIS Geostatistical Analyst (Nezammahalleh et al., 2013). Thus, we have two sets of data layers for the two periods. The changes in the surface area have also been determined by enhanced algorithm made based on Landsat images (Reveshty and Maruyama; 2010). For the first time, here, two interpolated precipitation layers have been used to be plugged into Student T-test equation in GIS in a spatial basis. To do this, the study area was divided to 25 regions based on drainage sub-basins. Less than 30 sample areas were randomly selected as cases from each of the regions to put into the equation. The discharge data were also compared for the two periods.

\section{RESULTS AND DISCUSSION}

The distribution of precipitation in the study area shows higher annual precipitation values $(870 \mathrm{~mm})$ in the southern part of the 
lake and lower values (less than $200 \mathrm{~mm}$ ) in the northeastern areas. These values have fluctuated insignificantly in the two periods before and after the construction of the causeway bridge across the lake (Figure 2).
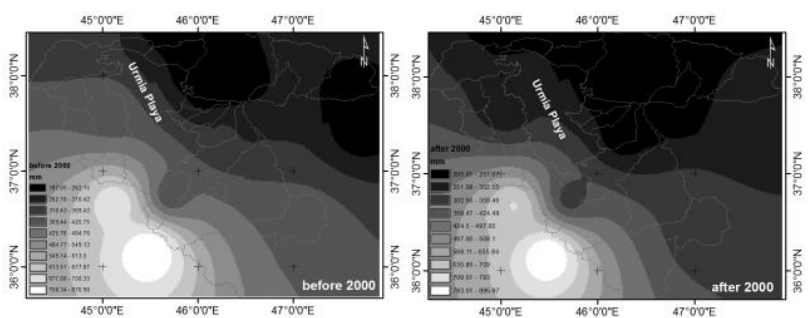

Figure 2: precipitation distribution in the study area

The results of satellite image processing also indicated a declining trend in the surface area of the lake from 1976 to 2010. It can also be observed in the images that the declining trend has been sharply intensified after 2000 (Figure 3). (Fahimi and Nezammahalleh, 2015)

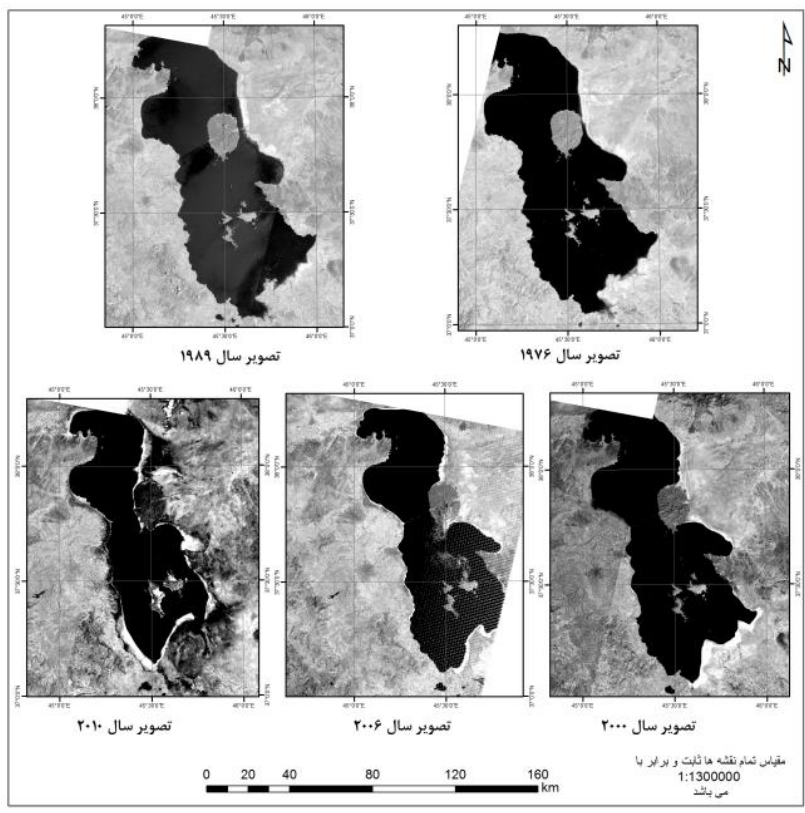

Figure 3: the drying trend of the Lake Urmia from 1976 to 2010 on the Landsat satellite images.

The result of $\mathrm{T}$ test is a calculatedlayer, representing $\mathrm{T}$ values for the sample pixels from the study area. The individual values of the sample areas from the layers were compared to the critical values of the Student's t distribution with an appropriate degree of freedom based on the number of samples. The t value for each sub basin is represented on a map to show different values of $\mathrm{T}$ in the study area. This helps to determine the areas wherein the differences in precipitation of the two periods are statistically significant. The results indicated that only some elevated areas in the north eastern part of the watershed of the lake do not have significant differences in precipitation (Figure 4). Furthermore, the results imply a reduction in water supply in the area.

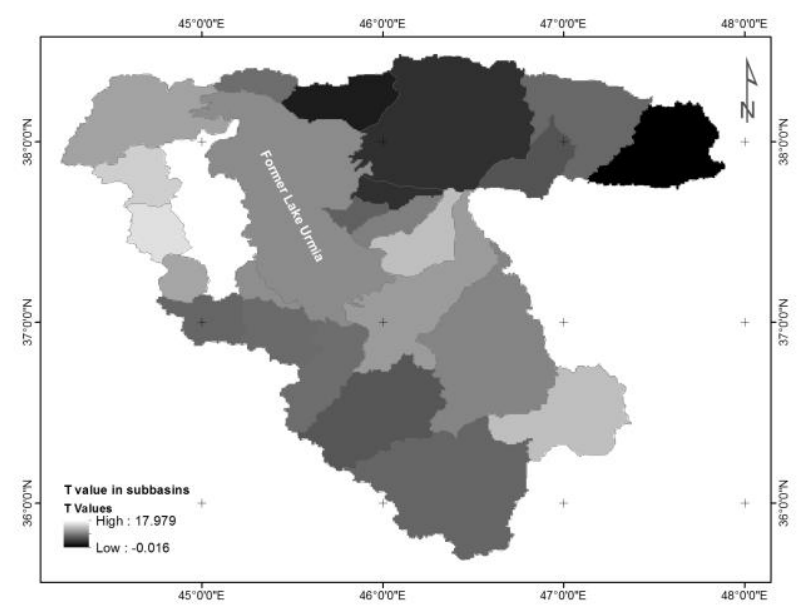

Figure 4: $t$ values in sub-basins of the Lake Urmia Watershed

Water discharge of some sample rivers of the watershed is indicative of a slightly declining trend. Determination of the discharge properties of the lake requires a more comprehensive study and the current research can only prove the decreasing trend of the river (Figure 5).

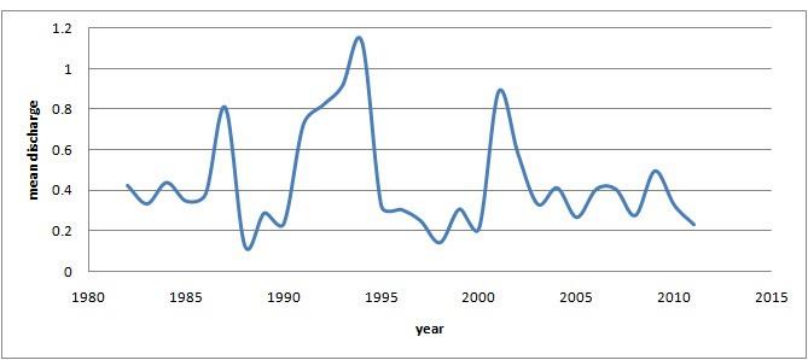

Figure 5: the river discharges trend

\section{CONCLUSION}

The changes in precipitation and generally climatic factors may be effective in reduction of water supplies in the elevated areas of the Urmia lake. Moreover, construction of the causeway bridge can affect the lake hydrodynamic conditions, thereby intensifying the drying trend in low height areas. The changes in precipitation may be indicative of the influence of climatic factors on the drying trend relative to agricultural and urban uses of water resources. The method of applying T-test in a spatial basis can also be influential in spatial inferences.

\section{REFERENCES}

Alavipanah, S. K., Nezammahalleh M. A., 2013, The Relationship of Salt Classification with Distance to Shoreline and Elevation, Case Study Lake Urmia, Iran. Journal of Environmental Treatment Techniques,Vol. 1, No. 1, PP. 35-37.

Ghahroudi Tali, M.; Nezammahalleh, M. A., (2013) Urban flooding management using the natural drainage system case study: Tehran, Capital of Iran, Floods: From Risk To Opportunity, IAHS Publ. 357, 174-180 
Jalili, S., Kirchner I., Livingstine D., Morid S., 2011, the influence of large-scale atmospheric circulation weather types on variations in the water level of Lake Urmia, Iran. International Journal of Climatology, Vol. 32, No. 13, PP. 1990-1996.

Nezammahalleh, M. A., $\quad$ Noori, A. A., Afsharmanesh, H., Pourhosseini, Z., $\quad$ Rastegar, A., $\quad$ Rezai, H. S. S., $\quad$ and Alavipanah, S. K.: IDENTIFICATION OF ACTIVE AREAS OF EARTHQUAKE BY THERMAL REMOTE SENSING, Int. Arch. Photogramm. Remote Sens. Spatial Inf. Sci., XL-1/W3, 295-299, doi: 10.5194/isprsarchives-XL-1-W3-295-2013, 2013.

Reveshty, M., Maruyama Y., 2010, Study of Urmia Lake Level Fluctuations and Predict Probable Changes Using MultiTemporal Satellite Images and Ground Truth Data Period (1976-2010). Paper presented at the Map Asia 2010 and ISG 2010, Kuala Lumpur, Malaysia.

S. Sima; M. Tajrishy, (2013) using satellite data to extract volume-area-elevation relationships for Urmia Lake, Iran, Journal of Great Lakes Research 39, 90-99

United Nations Environment Programme (UNEP) Global Environmental Alert Service (GEAS), (2012) The drying of Iran's Lake Urmia and its environmental consequences. Environmental Development 2, 128-137

Zeinoddini M.; Tofighi M.A., Vafaee F., 2009, Evaluation of dike-type causeway impacts on the flow and salinity regimes in Urmia Lake, Iran; Journal of Great Lakes Research 35, 13-22

Fahimi S.; Nezammahalleh, M.A.; (2015) Investigation about the Effects of Drying of Lake Urmia on Local Climate, 1st national conference of Iran meteorology, Yazd, Iran 